\title{
Submerged Gas Jet Penetration: A Study of Bubbling Versus Jetting and Side Versus Bottom Blowing in Copper Bath Smelting
}

\author{
JOËL P.T. KAPUSTA (1) ${ }^{1,2}$ \\ 1.-BBA Inc., 2020 Robert-Bourassa Blvd., Suite 300, Montréal, QC H3A 2A5, Canada. \\ 2.—e-mail: joel.kapusta@bba.ca
}

\begin{abstract}
Although the bottom blowing ShuiKouShan process has now been widely implemented in China, in both lead and copper smelters, some doubts, questions, and concerns still seem to prevail in the metallurgical community outside China. In the author's opinion, part of these doubts and concerns could be addressed by a better general understanding of key concepts of submerged gas injection, including gas jet trajectory and penetration, and the concept, application, and benefits of sonic injection in jetting regime. To provide some answers, this article first offers a discussion on the historical developments of the theory and mathematical characterization of submerged gas jet trajectory, including the proposed criteria for the transition from bubbling to jetting regime and the application of the Prandtl-Meyer theory to submerged gas jets. A second part is devoted to a quantitative study of submerged gas jet penetration in copper bath smelting, including a comparison between bubbling and jetting regimes, and side versus bottom blowing. In the specific cases studied, the calculated gas jet axis trajectory length in jetting regime is $159 \mathrm{~cm}$ for bottom blowing, whereas it varies between 129 and $168 \mathrm{~cm}$ for side blowing for inclination angles of $+18^{\circ}$ to $-30^{\circ}$ to the horizontal. This means that side blowing in the jetting regime would provide a deeper penetration and longer gas jet trajectory than generally obtained by conventional bath smelting vessels such as the Noranda and Teniente reactors. The theoretical results of this study do corroborate the successful high-intensity practice of the slag make converting process at Glencore Nickel in Canada that operates under high oxygen shrouded injection in the jetting regime, and this would then suggest that retrofitting conventional low-pressure, side-blowing tuyeres of bath smelting and converting reactors with sonic injectors in jetting regime certainly appears as a valuable option for process intensification with higher oxygen enrichment, without major process changes or large capital expenditure, i.e., no need for full reactor replacement.
\end{abstract}

\section{INTRODUCTION}

Research on submerged gas injection in pyrometallurgy has produced a wealth of knowledge over the last 60 years, with an apogee in the 1970s and 1980s. In these golden decades for applied research worldwide, both laboratory and plant trials were conducted to elucidate critical aspects of submerged gas injection, leading to the discovery of distinct bubbling and jetting regimes, the characterization of steady jetting conditions, or the quantification of gas penetration into molten baths. In 1990, Brimacombe, Nakanishi, Anagbo, and Richards exhaustively documented the breadth of this newly acquired global knowledge of the time in a 70-page seminal paper on injection with more than 270 references. ${ }^{1}$

Yet, despite numerous research breakthroughs on gas injection phenomena and some notable applications that revolutionized the steelmaking industry, the copper bath smelting and converting practice in cylindrical horizontal vessels has remained an 
inherently inefficient bubbling process up until the late 2000s. In that decade, China ENFI Engineering Corporation (ENFI) and Dongying Fangyuan of China brought back to the forefront of the nonferrous metals industry the concept of sonic bottom blowing of highly oxygen enriched air, and applied it to copper matte smelting in their bottom blowing ShuiKouShan (SKS) process in Vietnam and China. ${ }^{2,3}$ Seasoned readers will certainly recall that bottom blowing with shrouded tuyeres was invented for steelmaking by Savard and Lee in Canada in the $1960 \mathrm{~s}^{4-10}$ and industrially pioneered in nonferrous metals by Lurgi in the 1980 s, when they implemented lead sulfide smelting in Germany with the process conceived by Queneau and Schuhmann, which became known as the Queneau, Schuhmann, Lurgi, or Queneau-Schuhmann-Lurgi (QSL), process. $^{11-14}$ For reference, in 2013, Kapusta ${ }^{15}$ and Kapusta and Lee ${ }^{16}$ provided a fairly comprehensive historical perspective on the Savard-Lee tuyere development over three decades (1940s-1960s) and its subsequent adoption and adaptation from ferrous to nonferrous pyrometallurgy in the following four and a half decades (1970s-present).

Although the SKS process has now been widely applied in China, with about 50 lead smelters and more than 10 copper smelters in operation, with another half dozen being under construction, according to Wu Shaohui of ENFI, ${ }^{17}$ some doubts, questions, and concerns continue to be raised in the metallurgical community outside China. Are these concerns legitimate, although typical for any new technology in its early deployment phase, or is the global nonferrous industry missing an opportunity for a major step change? Although this article does not pretend or aim to provide a complete answer, reviewing specific aspects related to submerged gas injection, however, presents an opportunity to challenge the general understanding-or misunderstanding-around the concepts of bubbling and jetting regimes. In particular, the notions of gas jet trajectory and penetration are well worth revisiting theoretically and practically as they truly define the differences in terms of process efficiency and intensity between the traditional bubbling regime of the Noranda Reactor or Teniente Converter and the higher intensity jetting regime under sonic flow conditions of the SKS and QSL processes or the slag make converting (SMC) vessel. ${ }^{16}$

This article is composed of two main parts: (1) a discussion on the historical developments of the theory and mathematical characterization of submerged gas jet trajectory, including the proposed criteria for the transition from bubbling to jetting and the application of the Prandtl-Meyer theory to submerged gas jet, and (2) a quantitative study of submerged gas jet penetration in copper bath smelting, including a comparison between bubbling and jetting regimes, and side versus bottom blowing.

\section{SUBMERGED GAS JET TRAJECTORY}

One limitation to higher oxygen enrichment of blast air in smelting and converting vessels is the proportional increase in refractory erosion at the tuyere line. This refractory wear rate increase with higher oxygen is generally attributed to the more intense oxidation reactions in the bath occurring in the vicinity of the brick lining at and above the tip of the tuyeres. In that respect, the gas penetration-or lack of penetration-into the bath has a significant impact on the life span of the refractory lining, and consequently, it puts a stringent limit on the operating oxygen enrichment level compatible with a commercially viable reactor campaign length. This section will therefore focus on the theory and mathematical characterization of submerged gas jet trajectory as a first step toward predicting gas jet penetration in copper matte or white metal.

\section{Early Mathematical Formulation}

As a testament to the quality and originality of the research done in the $1960 \mathrm{~s}$ and $1970 \mathrm{~s}$, the mathematical formulation of a gas jet trajectory and penetration into a liquid, developed by Themelis, Tarassoff, and Szekely ${ }^{18}$ and based on continuity and momentum balances, has served as a reference for metallurgists around the world since its publications in 1969. The formulation of their model to predict the axis trajectory of a gas jet inclined at an angle, $\theta_{0}$, to the horizontal is provided in Eq. 1:

$$
\frac{\mathrm{d}^{2} y_{\mathrm{r}}}{\mathrm{d} x_{\mathrm{r}}^{2}}=\frac{4}{N_{\mathrm{Fr}^{*}}}\left(\frac{\tan ^{2}\left(\frac{\theta_{\mathrm{c}}}{2}\right)}{\cos \theta_{0}}\right) \sqrt{1+\left(\frac{\mathrm{d} y_{\mathrm{r}}}{\mathrm{d} x_{\mathrm{r}}}\right)^{2}} x_{\mathrm{r}}^{2} C .
$$

with $y_{\mathrm{r}}=y / d_{0}, x_{\mathrm{r}}=x / d_{0}, d_{0}$ is the tuyere orifice diameter, $N_{\mathrm{Fr}^{*}}$ is the modified Froude number, $\theta_{\mathrm{c}}$ is the cone angle or initial expansion angle, and $C$ is the average gas fraction across the jet at $x_{\mathrm{r}}$ given by Eq. 2 where $\rho_{\mathrm{l}}$ and $\rho_{\mathrm{g}}$ are the liquid and gas densities:

$$
C=\frac{\left(1-\frac{\rho_{1}}{\rho_{\mathrm{g}}}\right)+\sqrt{\left(1-\frac{\rho_{1}}{\rho_{\mathrm{g}}}\right)^{2}+16 \frac{\rho_{1}}{\rho_{\mathrm{g}}} x_{\mathrm{r}}^{2} \tan ^{2}\left(\frac{\theta_{\mathrm{c}}}{2}\right)}}{8 x_{\mathrm{r}}^{2} \tan ^{2}\left(\frac{\theta_{\mathrm{c}}}{2}\right)} .
$$

The modified Froude number, $N_{\mathrm{Fr}^{*}}$, is defined as follows:

$$
N_{\mathrm{Fr}^{*}}=\frac{\rho_{\mathrm{g}} u_{\mathrm{o}}^{2}}{g\left(\rho_{\mathrm{l}}-\rho_{\mathrm{g}}\right) d_{\mathrm{o}}}
$$

where $u_{\mathrm{o}}$ is the nominal gas jet velocity at the tuyere orifice, $g$ is the acceleration of gravity, and $d_{0}$ is the tuyere orifice diameter.

Equation 1 is a second-order nonlinear equation that can be numerically solved with the RungeKutta method using the following boundary conditions: 


$$
\begin{gathered}
y_{\mathrm{r}}=0 \quad \text { at } \quad x_{\mathrm{r}}=\frac{1}{2 \tan \left(\frac{\theta_{\mathrm{c}}}{2}\right)} \quad \text { and } \\
\frac{\mathrm{d} y_{\mathrm{r}}}{\mathrm{d} x_{\mathrm{r}}}=\tan \theta_{0} \quad \text { at } \quad x_{\mathrm{r}}=\frac{1}{2 \tan \left(\frac{\theta_{\mathrm{c}}}{2}\right)} .
\end{gathered}
$$

The diagram on Fig. 1 illustrates a rising gas jet trajectory for a horizontal tuyere $\left(\theta_{0}=0\right)$ and provides the mathematical characterization of the model as developed by Themelis et al. ${ }^{18}$

To validate their model, Themelis et al. ${ }^{18}$ used an experimental setup consisting of air injection into water in Plexiglass models of a Peirce-Smith converter. With a long exposure photographic technique, they visualized and measured the trajectory of air jets into water at various tuyere diameters and gas velocities. Some of their photographs and one of their result graphs are reproduced for illustration in Figs. 2 and 3.

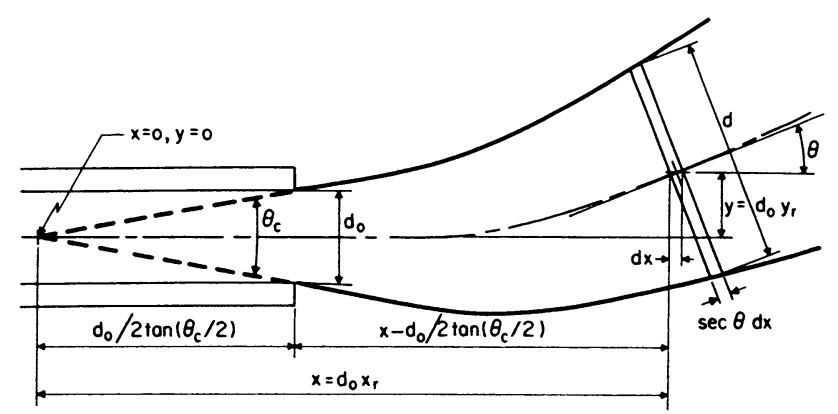

Fig. 1. Mathematical characterization of a rising gas jet trajectory. ${ }^{18}$

\section{Early Evaluation of the Jet Cone Angle}

One of the determining parameters in Eqs. 1 and 2 to predict jet axis trajectory is the jet cone angle, i.e., the angle at which the jet cone expands immediately after exiting the tuyere. By using their photographic technique, in their experiments, Themelis et al. ${ }^{18}$ measured an average jet cone angle of $20^{\circ}$. Applying this cone angle value in their jet penetration formulation, they obtained a very good agreement with their physical water model experiments. They believed that their air-water model results, including the cone angle value of $20^{\circ}$, could be extrapolated to the air-matte system of a PeirceSmith copper converter. Nevertheless, Oryall and Brimacombe ${ }^{19}$ demonstrated that the physical properties of the gas and liquid or molten bath had a

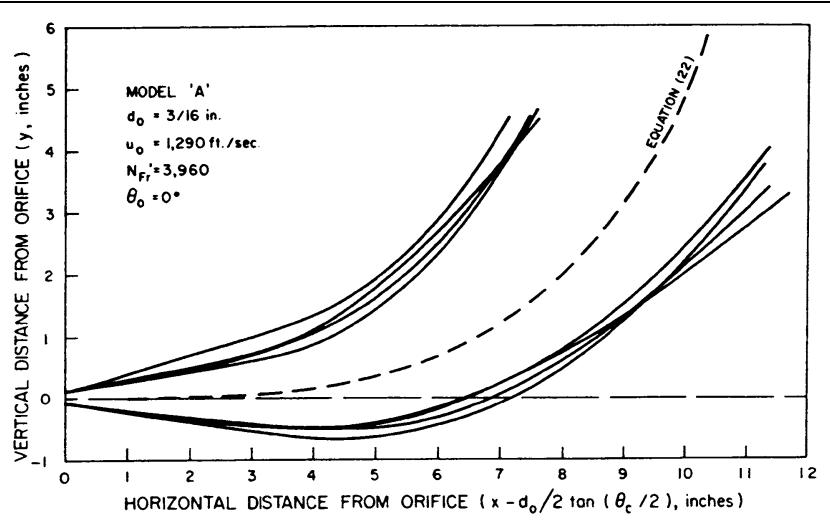

Fig. 3. Experimental results and predicted jet trajectory under the influence of buoyancy from Themelis et al. ${ }^{18}$ The dashed line represents the calculated jet axis trajectory while the solid lines represent the jet boundaries measured by long exposure photography. Note that Equation (22) on the figure corresponds to Eq. 1 in this article.
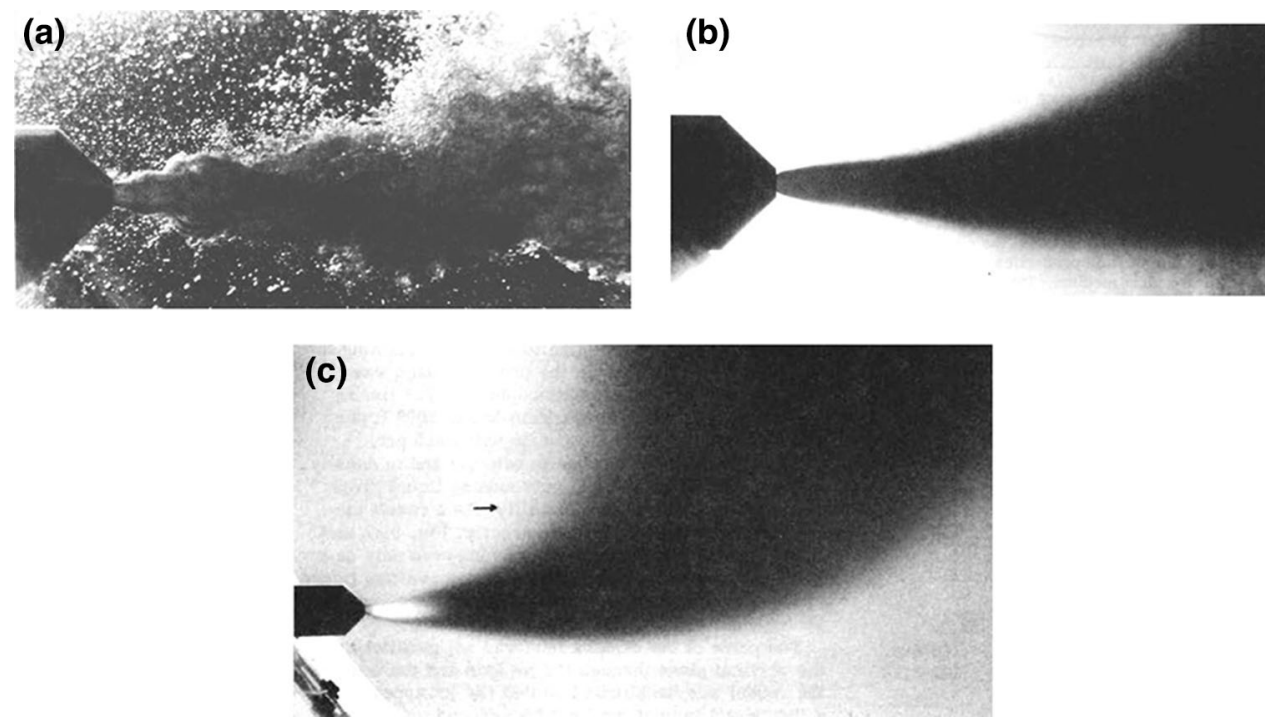

Fig. 2. Photographs of an air jet in water: (a) short time exposure $(0.6 \mathrm{~ms})$ illustrating the unstable jet, (b) long time exposure (5 s) visualizing the jet cone, and (c) long time exposure visualizing the influence of buoyancy. ${ }^{18}$ 
considerable impact on the jet dynamics. By comparing air injection in water and mercury under isothermal conditions, Oryall and Brimacombe ${ }^{19}$ revealed that the jet cone angle in mercury ranged between $150^{\circ}$ and $155^{\circ}$, a value more than seven times greater than the angle of air jets in water. By using an electroresistivity probe combined with an oscilloscope, they discovered that the forward air jet penetration in mercury was very limited. Although injected horizontally, the air jets in mercury appeared as if injected vertically.

Oryall and Brimacombe ${ }^{19}$ speculated that if density were the controlling physical property, then the cone angle of "process jets" such as air injected into copper matte, should have a value between air jets in mercury and in water because the density of copper matte lies between that of water and mercury. This would give a cone angle in the $70^{\circ}-100^{\circ}$ range. Yet, they also pointed out that if thermal expansion of the injected cold gas as a result of heat transfer from the hot molten bath is taken into account, process jets should expand faster than isothermal jets, and even faster if the reaction between the gas and bath is exothermic or produces a net increase in moles of gas, bringing the jet cone angle back to the $150^{\circ}-155^{\circ}$ range.

Hoefele and Brimacombe ${ }^{20}$ discovered and delineated in the laboratory two regimes of flow: bubbling and steady jetting. They complemented their research by industrial measurements during normal operation of a nickel converter at Inco's (at the time) Thompson Smelter in Manitoba and demonstrated that horizontally injected air into a converter was indeed discharging as discreet bubbles rising almost vertically, in a similar manner to air jets in mercury. One could then assume that the cone angle for air or oxygen enriched air injected into white metal or copper matte would have a value in the range $100^{\circ}-155^{\circ}$, and most likely in the upper portion of this range.

\section{Transition from Bubbling to Jetting Regime}

Applying Eq. 1 to predict a gas jet trajectory under bubbling regime is well established today. In fact, Asaki et al. ${ }^{21}$ refined the formulation for lowvelocity conditions as they believed the assumption of momentum conservation in the initial flow direction of Themelis et al. ${ }^{18}$ may not hold for discrete gas bubbles. On the other hand, to the best of his knowledge, the author is not aware of published work on the use of Eq. 1 for injection under jetting regime. In this respect, a key unknown is how to define the cone angle for jetting, which is intrinsically correlated to how the bubbling to jetting transition is characterized. Various criteria have been proposed over the years, either based on the modified Froude number, ${ }^{20,22}$ the Mach number, ${ }^{23,24}$ the "nominal" or underexpanded Mach number, ${ }^{20,25-28}$ the fully expanded Mach number, ${ }^{29}$ or even, during industrial plant trials, a criterion based on the minimum pressure necessary to keep the tuyeres opened. ${ }^{30-32}$ The author has repeatedly been questioned over the years about his own methodology for designing punchless sonic injectors and has experienced scepticism when responding that his criterion was not based on $N_{\mathrm{Fr}^{*}}$ per se. Some explanations are certainly warranted, and this article offers an opportunity to provide them.

If Hoefele and Brimacombe ${ }^{20}$ were the first in the English technical literature to delineate the flow regimes of bubbling and jetting as a function of $N_{\mathrm{Fr}^{*}}$ and the ratio of gas to liquid density, Sharma ${ }^{22}$ argued that their $N_{\mathrm{Fr}^{*}}$ value range of 300-900 for the bubbling to jetting transition was insufficient to avoid metal penetration into the tuyeres during inert gas injection into molten iron or steel. Sharma asserted that metal penetration in the tuyere was indeed controlled by $N_{\mathrm{Fr}^{*}}$ but not by the gas velocity, meaning not by the Mach number, and suggested $N_{\mathrm{Fr}^{*}}$ values of 2400-2500 or higher were necessary. Defining a criterion based on $N_{\mathrm{Fr}^{*}}$ poses a problem as $N_{\mathrm{Fr}^{*}}$ depends on the inverse of the tuyere diameter and on the gas and liquid densities. This means that any $N_{\mathrm{Fr}^{*}}$ criterion, such as that of Sharma, ${ }^{22}$ is only valid for a given gas-liquid system; i.e., given densities, and for a given tuyere diameter. Sharma's criterion certainly held true within the context of his experiments and application of inert gas injection into molten iron and steel with tuyeres of $1-3 \mathrm{~mm}$ in diameter. What would then be the $N_{\mathrm{Fr}^{*}}$ criterion for oxygen enriched air injected into molten white metal with a $20-40-\mathrm{mm}$ diameter tuyere?

Seemingly in opposition to Sharma's criterion, Farmer et al. ${ }^{29}$ stated that "it is generally agreed that sonic velocity at the tuyere exit is required to attain jetting flow, thereby preventing the backflow of metal into the tuyere." As a matter of fact, 10 years earlier, Hoefele and Brimacombe ${ }^{20}$ had observed that for systems with a low gas-to-liquid density ratio, underexpanded flow conditions, and therefore sonic velocity in the tuyeres, were necessary for steady jetting.

Based on the author's experience, sonic flow conditions are indeed necessary but not necessarily sufficient. In that respect, Mori et al. ${ }^{25}$ stipulated that "the value of the critical gas-flow velocity is a little bit larger than but very close to the nominal sonic velocity." By accounting for the compressibility property of gases, they derived a relationship for the nominal Mach number, $M^{\prime}$, as follows:

$$
\frac{P_{\mathrm{o}}}{P_{\text {metal. }}}=\sqrt{\frac{2}{k+1}} M^{\prime}
$$

where $P_{\mathrm{o}}$ is the gas pressure at the tuyere exit, $P_{\text {metal. }}$ is the metallostatic pressure, and $k$ is the gas specific heat ratio $C_{P} / C_{V}$. Equation 3 becomes a very simple expression for the subsonic to sonic boundary at the critical condition $P_{\mathrm{o}}=P_{\text {metal. }}$ : 


$$
M^{\prime}=\sqrt{\frac{k+1}{2}} \text { with } M^{\prime}=\frac{u_{\mathrm{o}}}{a}
$$

where $a$ is the sonic velocity at ambient temperature. By applying their criterion for air injection $(k=1.4)$ into white metal, the subsonic to sonic boundary would occur at $M^{\prime}=1.1$, meaning steady jetting would be obtained when the nominal Mach number exceeds a value of 1.1. At this point, providing a definition of the nominal Mach number is important to grasping its concept in full and that of Hoefele and Brimacombe ${ }^{20}$ is both precise and concise:

The nominal Mach number is defined, under conditions of underexpanded flow, to be the Mach number that would obtain just beyond the tip of the tuyere if the gas discharging from the tip accelerated uniformly in the flow direction and attained the local pressure measured at the tip. This, of course, is a fictitious number because the gas undergoes a multidirectional expansion at the tip, but it gives a measure of the degree of underexpansion of the jet.

\section{Prandtl-Meyer Theory Applied to Submerged Gas Injection}

In compressible fluid flow theory, expansion waves generated when a gas flow experiences a decrease in pressure are well described and characterized. These expansion waves can be generated when, as per Oosthuizen and Carscallen, ${ }^{33}$ "a supersonic gas flow passes over a convex corner or when the end of a duct containing a gas at a pressure that is higher than in the surrounding air is suddenly opened." Such gas flows are called Prandtl-Meyer flows.

Applying the Prandtl-Meyer theory of expansion wave to sonic gas flow in a tuyere discharging into liquid metal would certainly appear as a major leap. Based on the research work of Love et al. ${ }^{34}$ on gas discharge into free air, Ozawa and $\mathrm{Mori}^{26,27}$ made that leap and speculated that an underexpanded gas jet attaining sonic flow at the tuyere exit would discharge as a supersonic jet into molten metal. They derived the formulation to characterize the supersonic jet initial expansion angle (or cone angle) and the fully expanded Mach number as follows:

$$
\begin{aligned}
\theta_{\mathrm{c}}= & 2 \sqrt{\frac{k+1}{k-1}} \tan ^{-1}\left(\sqrt{\frac{k-1}{k+1}\left(M_{\text {exp }}^{2}-1\right)}\right) \\
& -\tan ^{-1}\left(\sqrt{M_{\text {exp }}^{2}-1}\right) \\
M_{\text {exp } .}^{2}= & \sqrt{\left[\left(\frac{P_{\text {exit }}}{P_{\text {metal. }}}\right)^{(k-1) / k}\left(\frac{k+1}{2}\right)-1\right] \frac{2}{k-1}}
\end{aligned}
$$

where $M_{\text {exp. }}$ is the fully expanded Mach number of the supersonic jet and $P_{\text {exit }}$ is the gas pressure at the tuyere exit. By substituting Eq. 3 into Eq. 6, a simple relationship between $M_{\text {exit }}$ and $M^{\prime}$ is obtained for air, oxygen, and nitrogen $(k=1.4)$ as follows:

$$
M_{\text {exp }}^{2}=5.845 M^{\prime 2 / 7}-5 .
$$

Substituting the critical value of $M^{\prime}=1.1$ from the subsonic to sonic boundary of Mori et al. ${ }^{25}$ into Eq. 7 gives, interestingly, a value of $M_{\text {exp. }}=1.0$. Equations 5 and 6 provide a means to calculate the initial expansion angle of a gas jet injected into white metal under jetting conditions. Using values of $M_{\text {exp }}$. between 1.0 (calculated at $M^{\prime}=1.1$ ) and 1.25 (corresponding to the criterion from Farmer et al. $^{29}$ ) gives a cone angle of $0^{\circ}-10^{\circ}$, which is considerably lower than the values of $150^{\circ}-155^{\circ}$ for injection into white metal under bubbling regime.

In the author's opinion, the necessary and sufficient condition for sonic injector design, including for matte smelting and converting, is that the fully expanded Mach number $M_{\text {exp., attains a critical }}$ value larger than unity. This condition ensures that the gas flow reaches Mach 1, i.e., sonic velocity, at the injector exit and that the gas flow is underexpanded. Although $M_{\text {exp. }}$ is mathematically independent of the injector diameter or the liquid-to-gas density ratio, as opposed to $N_{\mathrm{Fr}^{*}}$, based on the author's experience in sonic injection in both copper and nickel converting, the minimum or critical value of $M_{\text {exp }}$. required for jetting is impacted by the physical characteristics of the gas-molten bath system, particularly the gas flowrate and momentum and, therefore, indirectly to the injector diameter.

Sharma, ${ }^{22}$ Farmer et al., ${ }^{29}$ Ozawa et al. ${ }^{25-28}$ and Brimacombe et al., ${ }^{19,20}$ all carried out their laboratory work by using very small diameter tuyeres, in the range of 1-5 mm, intended for gas injection into molten iron and steel. Their criteria for jetting flow were therefore developed and tested for smalldiameter tuyeres. During plant trials of sonic injection in the late 1990s in a nickel matte converter at Falconbridge, now Glencore Nickel, the author had the opportunity to test the PrandtlMeyer theory and the bubbling to jetting transition criteria based on $M_{\text {exp. }}$ or $M^{\prime}{ }^{35}$

As anticipated, blowing with tuyere diameters larger than $18 \mathrm{~mm}$ had a marked impact on the critical value of $M_{\text {exp., certainly resulting from }}$ larger gas inertia and momentum of the larger gas flowrate injected. In the course of several trial campaigns, an optimum value was determined and tested. This new criterion for side blowing in nickel matte, together with an annular space design criterion, became a proprietary know-how that ensured the successful implementation of shrouded sonic injection in the Slag-Make Converter of Falconbridge 36,37 and Hoboken converters at Thai Copper, ${ }^{38,39}$ as well as of single-pipe sonic injection in a Peirce-Smith converter at Lonmin Platinum. ${ }^{40}$ 
Table I. Model assumptions for gas jet penetration comparison in copper bath smelting

\begin{tabular}{|c|c|c|}
\hline \multirow[t]{2}{*}{$\begin{array}{l}\text { Vessel dimensions } \\
\text { Vessel internal diameter }(\mathrm{m}) \\
\text { Average white metal level }(\mathrm{m}) \\
\text { Average slag level (bath depth) (m) }\end{array}$} & \multicolumn{2}{|l|}{$\begin{array}{l}4.00 \\
1.00 \\
1.70\end{array}$} \\
\hline & Side blowing & Bottom blowing \\
\hline $\begin{array}{l}\text { Injection parameters } \\
\text { Tuyere/injector submergence }(\mathrm{m}) \\
\text { Tuyere/injector angle (to vertical) }\left(^{\circ}\right) \\
\text { Bath density above tuyere/injector } \\
\quad\left(\text { mixture of slag and white metal) }\left(\mathrm{kg} / \mathrm{m}^{3}\right)\right.\end{array}$ & $\begin{array}{c}1.00 \\
49 \\
4285\end{array}$ & $\begin{array}{l}1.55 \\
22 \\
4775\end{array}$ \\
\hline & Bubbling & Jetting \\
\hline $\begin{array}{l}\text { Injection parameters } \\
\text { Tuyere/injector internal diameter }\end{array}$ & $54 \mathrm{~mm}$ & $\begin{array}{c}40 \mathrm{~mm} \text { (side) } \\
36 \mathrm{~mm} \text { (bottom) }\end{array}$ \\
\hline $\begin{array}{l}\text { Blowing rate per tuyere/injector }\left(\mathrm{Nm}^{3} / \mathrm{h}\right) \\
\text { Tuyere/injector oxygen enrichment }(\%) \\
\text { Cone angle (initial expansion angle) }\left(^{\circ}\right)\end{array}$ & $\begin{array}{c}1300 \\
38 \\
150\end{array}$ & $\begin{array}{c}2300 \\
50 \\
20\end{array}$ \\
\hline
\end{tabular}

\section{SUBMERGED GAS JET PENETRATION}

After discussing, in the previous section, the theory and mathematical characterization of submerged gas jet trajectory, as a first step toward predicting gas jet penetration in copper matte or white metal, this section provides a quantitative study of submerged gas jet penetration in copper bath smelting, first with a comparison between bubbling and jetting regimes, both in side blowing, and then between side versus bottom blowing, both in the jetting regime. The process conditions and vessel dimensions chosen for this comparison are given in Table I. The gas jet axis trajectories are calculated with Eq. 1, and the initial expansion angles for jetting are calculated with Eqs. 5 and 6 . For this comparison, jet cone angles of $150^{\circ}$ for bubbling (lower end of the $150^{\circ}-155^{\circ}$ range measured by Oryall and Brimacombe ${ }^{19}$ ) and $20^{\circ}$ for jetting (twice the angle from the critical angle of Farmer et al. $^{29}$ ) were chosen to remain on the conservative side and still demonstrate the difference in forward gas penetration between the bubbling and jetting regimes.

\section{Bubbling Versus Jetting in Side Blowing}

The effect of the jet cone angle on gas penetration in the bubbling regime for side blowing is illustrated on Fig. 4. The curves on the figure represent the idealized centerline or axis of the gas jet trajectory as calculated with Eqs. 1 and 2. The reader should remember that the actual jet has wider boundaries, as shown on Fig. 2, than this calculated gas jet axis trajectory. Qualitatively, penetration increases with decreasing cone angle and the forward penetration distance from the tuyere tip obtained for the various cone angles is in good agreement with the results from Themelis et al. ${ }^{18}$ Figure 5 provides a

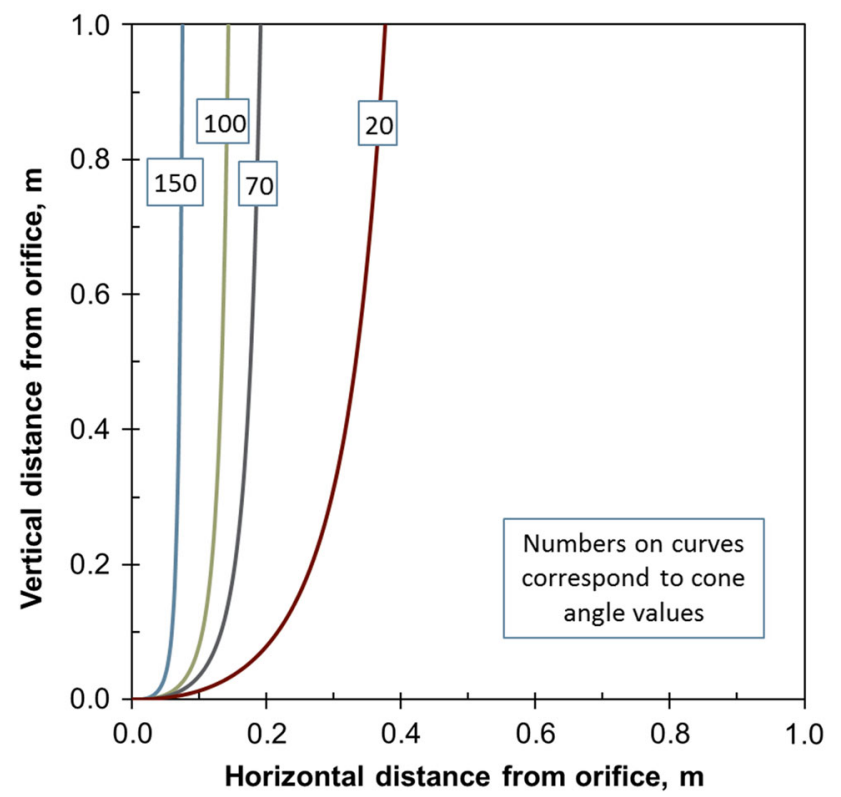

Fig. 4. Effect of jet cone angle on gas penetration for bubbling side blowing.

comparison between the bubbling and jetting regimes for side blowing. Under the conditions detailed in Table I, the calculated gas penetration under the jetting regime for side blowing is about seven times larger than for bubbling, even with the conservative cone angles chosen. The impact of the inclination angle, the angle of the tuyeres in relation to the horizontal, is illustrated on Fig. 6 for side blowing in the jetting regime. A negative angle, tuyeres inclined downward, gives a deeper and longer forward gas penetration until an inclination angle of about $-18^{\circ}$. Beyond this inclination angle, the forward penetration no longer increases. 


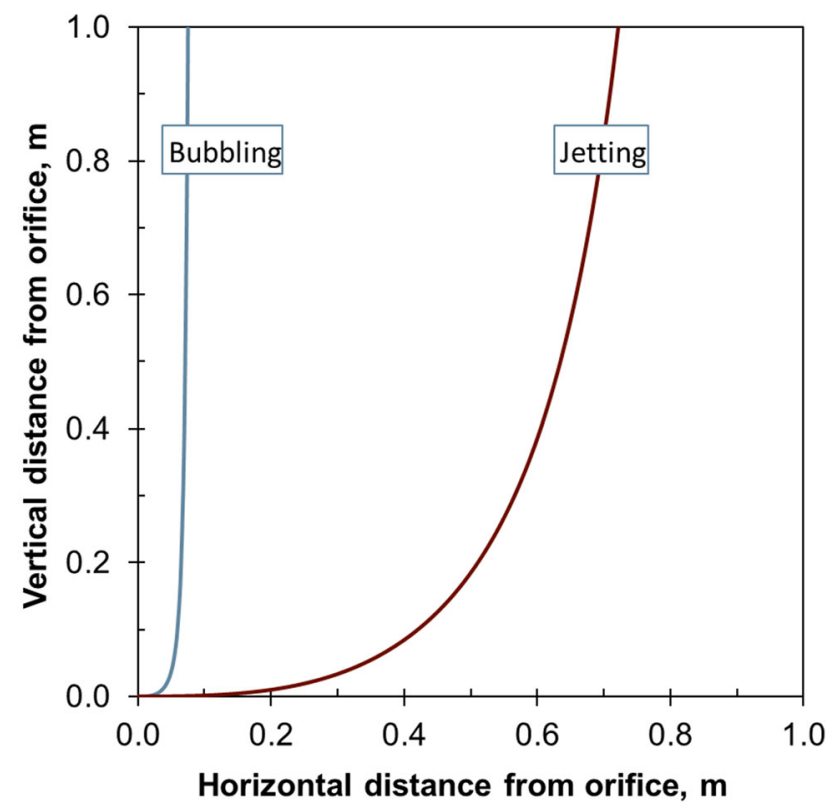

Fig. 5. Gas jet penetration for bubbling $\left(150^{\circ}\right)$ versus jetting $\left(20^{\circ}\right)$ for side blowing.

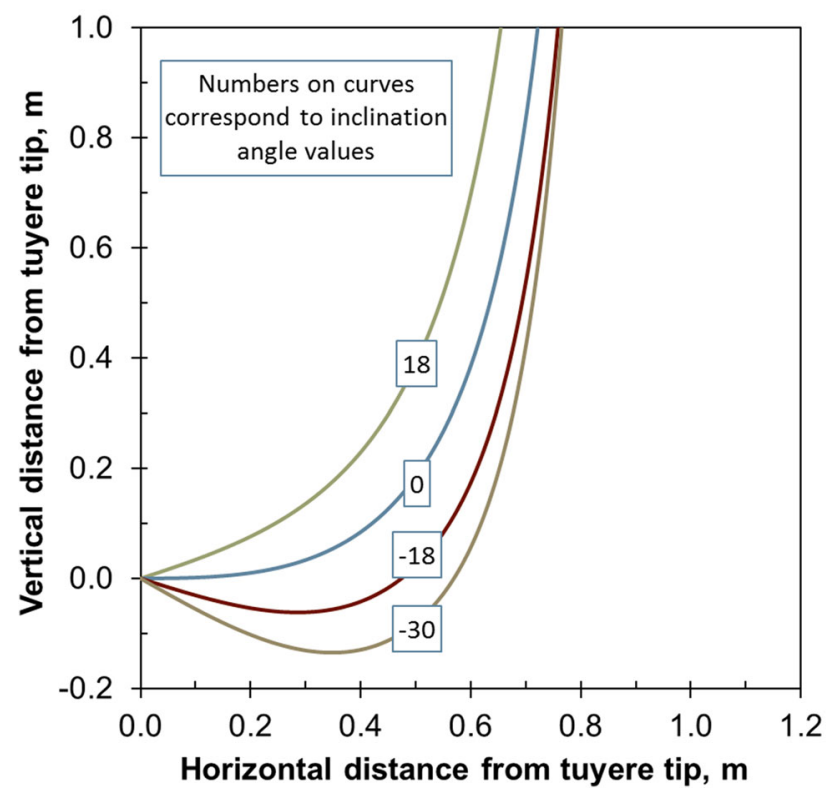

Fig. 6. Effect of inclination angle on gas jet penetration for side blowing jetting regime.

\section{Bubbling Versus Jetting in Side Blowing}

A comparison of the gas jet axis trajectory for side and bottom blowing, both in the jetting regime, is given in Fig. 7. Again, the curves on the figure represent the idealized gas jet axis trajectory as calculated with Eqs. 1 and 2. The graph clearly shows that gas penetration away from the side wall in bottom blowing is essentially a result of the location of the tuyere tip deeper and closer to the center of the vessel compared to side blowing. The

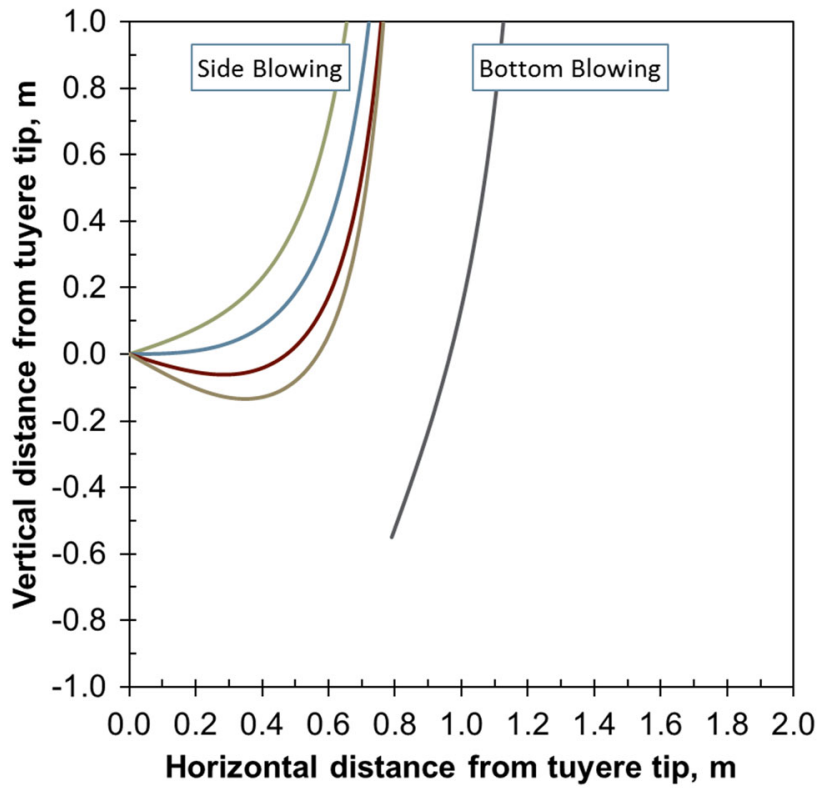

Fig. 7. Gas jet penetration for side versus bottom blowing in jetting regime.

gas jet axis trajectory is slightly curved because the studied conditions are not truly "bottom blowing," the tuyere being at a $22^{\circ}$ angle from the vertical.

Another element of comparison is the length of the gas jet axis trajectories, that can be calculated with the arc length numerical method using Simpson's rule. A longer trajectory length means a longer time for gas-bath interactions. The trajectory lengths calculated for side blowing are 129, 141, 156 , and $168 \mathrm{~cm}$ for inclination angles of $+18^{\circ}, 0^{\circ}$, $-18^{\circ}$, and $-30^{\circ}$, respectively. The trajectory length calculated for bottom blowing is $159 \mathrm{~cm}$, just slightly longer than for side blowing at an inclination angle of $-18^{\circ}$. If the calculated axis trajectory lengths are similar in this study for side blowing $\left(-18^{\circ}\right.$ inclination) and bottom blowing $\left(22^{\circ}\right.$ angle from vertical), the more significant difference in practice, in the author's opinion, resides on the recirculation matte and slag flow patterns generated by side blowing compared with bottom blowing. A computational fluid dynamic (CFD) model, which is beyond the scope of this article, would provide insights into the recirculation matte flow within the vessel. Such a model would certainly be valuable to evaluate gas stirring capabilities, particularly if concentrate is added from the top via feed ports or chutes.

To visualize side and bottom blowing better, both in the jetting regime, a scaled diagram of the smelting vessel with the dimensions provided in Table I is presented in Fig. 8. The diagram offers a comparison of the gas jet trajectories for a side blowing tuyere positioned at a $49^{\circ}$ angle from the vertical and inclined by $-18^{\circ}$ from the horizontal and a bottom blowing tuyere positioned at a $22^{\circ}$ angle from the vertical and installed radially. Once 


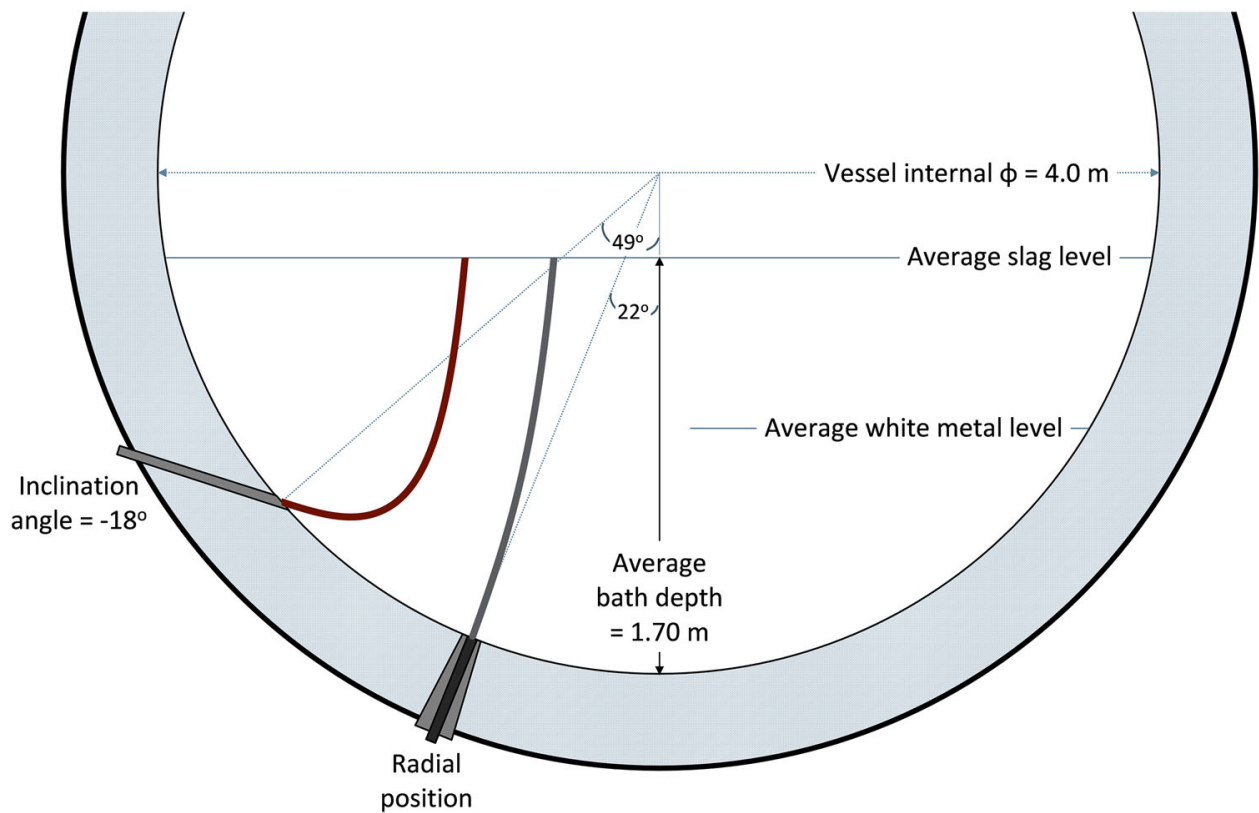

Fig. 8. Scaled drawing of Cu smelting vessel with dimensions from Table I. Visualization of the calculated gas jet axis trajectories under jetting regime for side blowing (inclination of $-18^{\circ}$ ) and bottom blowing (radial position).

again, the "idealized" gas jet axis trajectory curves in Fig. 8 represent the calculated axis trajectories. The actual gas jet boundaries widen as the gas penetrates into the bath and away from the tuyere tip. The width of the gas jet depends on several parameters, including the initial expansion angle, the gas and bath densities, as well as the tuyere orifice diameter, inclination angle, and submergence.

\section{CONCLUSION}

The following conclusions can be drawn from this short submerged gas jet penetration study of bubbling versus jetting regimes and side blowing versus bottom blowing:

1. Operating under jetting conditions for side blowing provides a major improvement compared with bubbling in terms of gas jet penetration into the bath and away from the tuyere line refractory, as shown in Fig. 5. In conventional low-pressure injection, gas bubbles grow at the tip of the tuyeres and essentially rise vertically above the tuyere tips. With sonic underexpanded conditions, i.e., in the jetting regime, and depending on the tuyeres inclination angle, the results of this study show that the gas jet axis penetrates $30-60 \mathrm{~cm}$ into the bath before curving upward as a result of buoyancy forces.

2. Retrofitting conventional low-pressure, sideblowing tuyeres of bath smelting (and converting) reactors with sonic injectors in the jetting regime certainly appears as a very promising option considering the 30 - to 60 -cm gas jet axis forward penetration, the 129 to $168-\mathrm{cm}$ gas jet axis trajectory length, and the beneficial growth of a protective accretion at the tip of the sonic tuyeres. Sonic injection would not only improve smelting intensity but would also improve oxygen efficiency by minimizing or eliminating leaks at the tuyere body connections (benefit of punchless operation). When appropriate, retrofitting an existing bath smelting vessel would be much less capital intensive than replacing that smelting vessel.

3. Bottom blowing under the jetting regime does provide injection conditions with a long gas jet axis trajectory through the bath at a much greater distance from the barrel wall and through a thicker layer of matte or white metal. These bottom blowing conditions should be beneficial in terms of lower refractory erosion and high oxygen efficiency.

4. For both side and bottom blowing in the jetting regime, injectors must be designed and operated to maintain sonic flow while ensuring the degree of underexpansion is sufficient, yet not too large, so that the gas jet exiting at sonic velocity at the tip of the tuyere becomes supersonic immediately after exiting the tuyere (Prandtl-Meyer flow).

From a purely theoretical perspective, this study of gas jet penetration into molten copper baths may seem incomplete to some readers, or even incorrect, since neither the Kelvin-Helmholtz (KH) and Rayleigh-Taylor (RT) instabilities nor the impact of surface tension of the molten bath have been considered. For instance, the wealth of literature available, particularly in physics and fluid dynamics 
journals, has shown that $\mathrm{KH}$ and $\mathrm{RT}$ instabilities significantly impact air jet penetration into stagnant water.

Nevertheless, two key differences between the air-water and air-molten copper systems in terms of gas jet behavior are the high temperature and the 4- to 7-fold higher density of molten copper matte and slag compared to water. Although good models to predict air jet penetration into water have been developed and validated by cold model experiments, the same cannot be said for air or oxygen injection into molten metals. At best, a gas jet penetration trend can be calculated for comparison purposes, as done in this study.

The value of this present study and injector design approach, even if theoretically incomplete, is that sonic injectors designed by the author based on the described Prandtl-Meyer flow theory, have proven to work in commercial operations. Here, the term "work" means that the injectors operate in a punchless mode, without blockage, at a constant controlled gas flowrate, with significantly less splashing, and with a life span sufficiently long to allow the process to be financially viable in a Western economic model. So far, this has been good enough for the author's clients to meet their process improvement goals.

Nevertheless, with a trend toward more and more demanding constraints on the process operation to improve the energy efficiency, work hygiene, and environmental footprint of copper smelting, converting, and refining vessels, gas injection technologies have to continuously improve to maintain the pace of change. In that respect, the author would welcome comments and suggestions from readers, particularly those experts in compressible fluid dynamics, on ways to better quantify the length of penetration of a gas jets into hot molten metals and slags. The objective is to continuously improve the design methodology for sonic injectors, particularly those with exit diameters in the range of $25-50 \mathrm{~mm}$ where the gas momentum impact is large.

\section{ACKNOWLEDGEMENTS}

The permission and support from BBA to prepare this article is gratefully acknowledged.

\section{REFERENCES}

1. J.K. Brimacombe, K. Nakanishi, P.E. Anagbo, and G.G. Richards, Proceedings of the Elliott Symposium on Chemical Process Metallurgy, eds. P.J. Koros and G.R. St. Pierre (Warrendale, PA: TMS, 1990), pp. 343-412.

2. K. Jiang, L. Li, Y. Feng, H. Wang, and B. Wei, Proceedings of the T.T. Chen Honorary Symposium on Hydrometallurgy, Electrometallurgy and Materials Characterization, eds. S. Wang, J.E. Dutrizac, M.L. Free, J.Y. Hwang, and D. Kim (Warrendale, PA: TMS, 2012), pp. 167-176.

3. B. Zhao, Z. Cui, Z. Wang, Fourth International Symposium on High-Temperature Metallurgical Processing, eds. T. Jiang, J.Y. Hwang, P.J. Mackey, O. Yucel, and G. Zhou (Warrendale, PA: TMS, 2013), pp. 3-10.

4. G. Savard and R. Lee, US Patent 2855293 (7 October 1958).
5. G. Savard and R. Lee, French Patent 1450718 (18 July 1966).

6. H. Knuppel, K. Brotzmann, H.G. Fassbieder, G. Savard, and R. Lee, U.S. Patent 3706549 (19 December 1972).

7. G. Savard and R.G.H. Lee, US Patent 4315774 (16 February 1982).

8. G. Savard and R.G.H. Lee, Proceedings of the Savard/Lee International Symposium on Bath Smelting, eds. J.K. Brimacombe, P.J. Mackey, G.J.W. Kor, C. Bickert, and M.G. Ranade (Warrendale, PA: TMS, 1992), pp. 645-660.

9. P.J. Mackey and J.K. Brimacombe, Proceedings of the Savard / Lee International Symposium on Bath Smelting, eds. J.K. Brimacombe, P.J. Mackey, G.J.W. Kor, C. Bickert, and M.G. Ranade (Warrendale, PA: TMS, 1992), pp. 3-28.

10. Proceedings of the Savard/Lee International Symposium on Bath Smelting, eds. J.K. Brimacombe, P.J. Mackey, G.J.W. Kor, C. Bickert, and M.G. Ranade (Warrendale, PA: TMS, 1992).

11. P.E. Queneau and R. Schuhmann, US Patent 3941587 (2 March 1976).

12. P.E. Queneau and R. Schuhmann, JOM 26, 2 (1974).

13. P.E. Queneau, JOM 41, 30 (1989).

14. P. Arthur, A. Siegmund, and M. Schmidt, Proceedings of the Savard/Lee International Symposium on Bath Smelting, eds. J.K. Brimacombe, P.J. Mackey, G.J.W. Kor, C. Bickert, and M.G. Ranade (Warrendale, PA: TMS, 1992), pp. $127-145$.

15. J.P. Kapusta, Proceedings of the Ralph Harris Memorial Symposium, eds. C. Harris, S. Kashani-Nejad, and M. Kreuth (Montreal, QC: The Materials and Metallurgical Society of CIM (METSOC), 2013), pp. 267-317.

16. J.P.T. Kapusta and R.G.H. Lee, Proceedings of Copper 2013 International Conference, Volume III (Book 2)-The Nickolas Themelis Symposium on Pyrometallurgy and Process Engineering, eds. R. Bassa, R. Parra, A. Luraschi, and S. Demetrio (Santiago, Chile: The Instituto de Ingenieros de Minas de Chile (IIMCh), 2013), pp. 523-558.

17. Wu Shaohui, Modern China Copper Industry Development and SKS Technology, China ENFI Engineering Corporation presentation at the 15th CRU World Copper Conference, Santiago, Chile, April 4-6, 2016.

18. N.J. Themelis, P. Tarassoff, and J. Szekely, Trans. Metall. Soc. AIME 245, 2425 (1969).

19. G.N. Oryall and J.K. Brimacombe, Metall. Trans. B 7, 391 (1976).

20. E.O. Hoefele and J.K. Brimacombe, Metall. Trans. B 10, 631 (1979).

21. Z. Asaki, H. Kakimi, K. Matsumoto, and Y. Kondo, Trans. Japan Inst. Metals 22, 841 (1981).

22. S.K. Sharma, I\&SM 14, 73 (1987).

23. T. Kimura, S. Tsuyuguchi, Y. Ojima, Y. Mori, and Y. Ishii, Paper No. A86-4 (Warrendale, PA: TMS, 1986).

24. T. Kimura, S. Tsuyuguchi, Y. Ojima, Y. Mori, and Y. Ishii, JOM 38, 38 (1986).

25. K. Mori, Y. Ozawa, and M. Sano, Trans. ISIJ 22, 377 (1982).

26. Y. Ozawa and K. Mori, Trans. ISIJ 23, 759 (1983).

27. Y. Ozawa and K. Mori, Trans. ISIJ 23, 764 (1983).

28. Y. Ozawa and K. Mori, Trans. ISIJ 26, 291 (1986).

29. L. Farmer, D. Lach, M. Lanyi, and D. Winchester, 72nd Steelmaking Conference Proceedings (Warrendale, PA: TMS, 1989), pp. 487-495.

30. A.A. Bustos, J.K. Brimacombe, and G.G. Richards, Internal Report (The Centre for Metallurgical Process Engineering, University of British Columbia, 1986).

31. A.A. Bustos, J.K. Brimacombe, G.G. Richards, A. Vahed, and A. Pelletier, Proceedings of the Copper 87-Cobre 87 International Conference, Vol. IV-Pyrometallurgy of Copper, eds. C. Diaz, C. Landolt, and A. Luraschi (Santiago, Chile: Universidad de Chile, 1987), pp. 347-373.

32. J.K. Brimacombe, S.E. Meredith, and R.G.H. Lee, Metall. Trans. B 15, 243 (1984).

33. P.H. Oosthuizen and W.E. Carscallen, Compressible Fluid Flow (New York: McGraw-Hill Inc., 1997). 
34. E.S. Love, C.E. Grigsby, L.P. Lee, and M.J. Woodling, NASA Technical Report R-6 (Langley Field, VA: Langley Research Centre, 1959).

35. A.A. Bustos, J.P. Kapusta, B.R. Macnamara, and M.R. Coffin, Proceedings of the Copper 99-Cobre 99 International Conference, Vol. VI-Smelting, Technology Development, Process Modeling and Fundamentals, eds. C. Diaz, C. Landolt, and T. Utigard (Warrendale, PA: TMS, 1999), pp. 93-107.

36. A.A. Bustos and J.P. Kapusta, Proceedings of the Brimacombe Memorial Symposium, eds. G.A. Irons and A.W. Cramb (Montreal, QC: The Metallurgical Society of CIM, 2000), pp. 107-124.

37. J.P. Kapusta, H. Stickling, and W. Tai, Proceedings of Converter and Fire Refining Practices, eds. A. Ross, T. Warner, and K. Scholey (Warrendale, PA: TMS, 2005), pp. 47-60.
38. J.P.T. Kapusta, N. Wachgama, and R.U. Pagador, Proceedings of Copper 2007-Cobre 2007 International Conference, Vol. III (Book 1)-The Carlos Diaz Symposium on Pyrometallurgy, eds. A.E.M. Warner, C.J. Newman, A. Vahed, D.B. George, P.J. Mackey, and A. Warczok (Montreal, QC: The Metallurgical Society of CIM, 2007), pp. 483-500.

39. R. Pagador, N. Wachgama, C. Khuankla, and J.P. Kapusta, Proceedings of the International Peirce-Smith Converting Centennial Symposium, eds. J.P.T Kapusta and A.E.M. Warner (Warrendale, PA: TMS, 2009), pp. 367-381.

40. J.P.T Kapusta, J. Davis, G.A. Bezuidenhout, S. Lefume, and D.K. Chibwe, Proceedings of the 51st Conference of Metallurgists-Towards Clean Metallurgical Processing for Profit, Social and Environmental Stewardship Symposium, eds. R. Schonewille, D. Rioux, S. Kashani-Nejad, M. Kreuh, and M.E.S. Muinonen (Montreal, QC: The Metallurgical Society of CIM, 2011), pp. 43-58. 